\title{
EVALUATION OF MATUROGENESIS AND APEXIFICATION TECHNIQUES IN THE MANAGEMENT OF TRAUMATIZED NON-VITAL IMMATURE PERMANENT INCISORS
}

\author{
Akram Elsayyad*, Manal Ahmed Elsayed* and Kamal Elmotayam*
}

\begin{abstract}
Introduction: Regenerative endodontics is a promising alternative treatment for immature teeth with necrotic pulps.
\end{abstract}

Aim of the study: The present study was performed to assess healing potential of young permanent immature teeth with necrotic pulp after the following treatment protocols: (1) Calcium hydroxide apexification, (2) the regenerative endodontic protocol (blood clot scaffold).

Materials and Methods: Immature necrotic permanent maxillary central incisors $(n=48)$ were divided into 2 groups according to the treatment protocol: the apexification group (calcium hydroxide), the REG group (regenerative endodontic protocol). Follow-up was done up to 18 months. Standardized radiographs were digitally evaluated for an increase in root length and thickness, a decrease in the apical diameter Follow-up was done up to 18 months.

Results: After a follow-up period of 18 months, most of the cases showed radiographic evidence of periapical healing. Groups showed a progressive increase in root length and width and a decrease in apical diameter.

Conclusions: The regenerative endodontic procedure allowed the continued development of roots in teeth with necrotic pulps.

KEY WORDS: Mineral trioxide aggregate, Regeneration, Apexification.

\section{INTRODUCTION}

The cessation of root development caused by trauma or pulpal disease presents both an endodontic and restorative challenge. Apexification is defined as a "method to induce a calcified barrier in a root with an open apex or the continued apical development of teeth with incomplete root in teeth with necrotic pulp' (1). Regenerative endodontics is a promising alternative treatment for immature teeth with necrotic pulps. A number of recent clinical case reports have revealed that many teeth that traditionally would receive apexification may be treated for apexogenesis. The ideal treatment

\footnotetext{
* Department of Pediatric dentistry and Dental Public Heath, Faculty of Dentistry, Cairo University.
} 
to obtain further root development and thickening of dentinal walls in an immature tooth with apical periodontitis would be to stimulate the regeneration of a functional pulp-dentin complex ${ }^{(2,3,4)}$. Efforts have been directed to procedures that enhance ingrowth of tissues into pulp spaces. These tissues lead to a radiographically observable hard tissue deposition in the root canals after some time $\left.{ }^{(5,6}\right)$. A call for a paradigm shift and new protocol for the clinical management of these cases has been brought to attention.

\section{MATERIALS AND METHODS}

Forty-eight immature, nonvital maxillary anterior teeth presenting with or without signs and/ or symptoms of periapical pathology were included in this study from the outpatient clinic of the Faculty of Dentistry, Cairo University. A detailed medical and dental history was obtained from each patient's parents or guardians. Children were apparently healthy and had no congenital or systemic chronic disease. Intraoral periapical radiographs revealed immature apices. The age of the patients ranged between 9 and 13 years. Informed consent was signed for each case by the patient's parents or guardians including the proposed treatment and possible outcomes or complications. The selected teeth were divided randomly into two main groups according to the technique used: Group A: Consisted of 26 teeth that were treated with regeneration (revascularization) technique. These 26 teeth were further subdivided into two subgroups:

- Subgroup I: consisted of 15 teeth treated with MTA.

- Subgroup II: consisted of 11 teeth treated with $\mathrm{Ca}(\mathrm{OH}) 2$

Group B: Consisted of 22 teeth that were treated with apexification technique. These 22 teeth were further subdivided into two subgroups:

- Subgroup I: consisted of 11 teeth treated with MTA.
- Subgroup II: consisted of 11 teeth treated with $\mathrm{Ca}(\mathrm{OH})_{2}$

Preoperative radiographs were taken using the standardized paralleling technique with the Rinn XCP alignment system preoperatively using standardized periapical radiographs and specially designed DigoraÒ software for image analysis

After local anesthesia and rubber dam isolation. A conventional access cavity was prepared in the palatal surface of the teeth using carbide burs. The root canal was irrigated copiously with $5.25 \%$ sodium hypochlorite $(\mathrm{NaOCl})$ using a hypodermic syringe. The canal space was dried using paper points. A sterile cotton pellet was then applied, and the access cavity was sealed using a temporary restoration for 2 weeks. The final visit was scheduled when the tooth was asymptomatic with no signs of discharge. After anesthesia and proper isolation, the temporary restoration and the cotton pellet were removed. The canal was irrigated with $10 \mathrm{~mL} \mathrm{NaOCl} 5.25 \%$ followed by $10 \mathrm{~mL}$ sterile saline and dried with sterile paper points. One of the following treatment modalities was randomly chosen.

\section{For Group A:}

Antimicrobial agents consisting of equal parts of metronidazol and ciprofloxacin in a paste form as intra-canal medication was applied using lentulo spiral. The access cavity was sealed with a cotton pellet and $2 \mathrm{~mm}$-thick temporary filling. After 1 week a sterile hand file size \#80 was used with sharp strokes into the periapical tissue $2 \mathrm{~mm}$ beyond the apex until bleeding was evident at the cervical portion of the canal. An MTA orifice plug was used to seal the canal orifice covered by a moist cotton pellet for subgroup I. while in subgroup II Calcium Hydroxide $\mathrm{Ca}(\mathrm{OH})_{2}$, paste was prepared by mixing $\mathrm{Ca}(\mathrm{OH}) 2$ powder with distilled water and rolled to form a robe that was inserted in the canal, followed by a thread of cotton and hand plugger condensation over the blood clot. After 1 week, adhesive composite resin was used to seal the access cavity. 


\section{For Group B}

The MTA apical plugs were placed by a standardized hand condensation technique of apical stop in all cases of Subgroup I. The thicknesses of the MTA apical plug varied from $3 \mathrm{~mm}$ to $5 \mathrm{~mm}$, which offers a good seal and allow the rest of the canal to be obturated by using thermoplasticized gutta purcha. The patient was instructed to wait in the waiting area for one hour to allow for the formation a firm barrier of MTA cement, which was assessed using a K File. The rest of the canal was backfilled with injectable thermoplasticized gutta percha which offers a her-

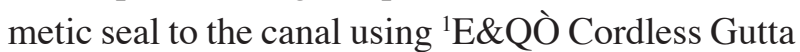
Percha Obturation Systems. While For Subgroup II Calcium Hydroxide $\mathrm{Ca}(\mathrm{OH})_{2}$ paste was prepared by mixing $\mathrm{Ca}(\mathrm{OH})_{2}$ powder with distilled water and rolled to form a robe that was inserted in the canal followed by a thread of cotton and endodontic plugger condensation until $\mathrm{Ca}(\mathrm{OH})_{2}$ reaches the end of canal. The access cavity was then sealed with glass ionomer and adhesive composite resin.

\section{Evaluation}

Patients were recalled at 3,6,12, and 18 months. Follow-up included the radiographic assessment for apical closure, root maturation and pulpal canal obliteration. Images of the treated teeth were manipulated using specially designed software of the DigoraÒ system.

\section{RESULTS}

Table (1) shows frequencies, percentages and results of chi-square test for comparison between apical closure, root maturation and pulpal canal obliteration (PCO) in the four subgroups. There was no statistically significant difference between prevalence of apical closure in the four subgroups $(\mathrm{P}$ value $=0.15)$. However Group A subgroup I showed the highest percentage $(73.3 \%)$, followed by Group B Subgroup I and II (72.7\%) followed by Group A Subgroup II (63.3\%).

There was a statistically significant difference between root maturation in the four subgroups ( $\mathrm{P}$ value $=0.001)$. Group A Subgroup I showed the highest prevalence of root maturation $(66,7 \%)$ followed by Group A Subgroup II (63.6\%). Group B Subgroup I showed lower prevalence of root maturation (18.1\%), while Group B Subgroup II showed no root maturation at all.

There was a statistically significant difference between pulpal canal obliteration (PCO) in the four subgroups $(\mathrm{P}$ value $=0.003)$. Group A Subgroup II showed the highest prevalence of PCO (63.6\%) followed by Group B Subgroup I (18.1\%). Group A Subgroup I showed lower prevalence (13.3\%) while Group B Subgroup II showed no PCO at all.

TABLE (1): Frequencies, percentages and results of chi-square test for comparison between apical closure, root maturation and pulpal canal obliteration (PCO) in the four subgroups.

\begin{tabular}{|c|c|c|c|c|c|}
\hline & $\begin{array}{c}\text { Group A } \\
\text { Subgroup I } \\
(\mathrm{n}=15 \text { teeth) }\end{array}$ & $\begin{array}{c}\text { Group A } \\
\text { Subgroup II } \\
(\mathrm{n}=11 \text { teeth) }\end{array}$ & $\begin{array}{c}\text { Group B } \\
\text { Subgroup I } \\
(\mathrm{n}=11 \text { teeth) }\end{array}$ & $\begin{array}{c}\text { Group B } \\
\text { Subgroup II } \\
(\mathrm{n}=11 \text { teeth) }\end{array}$ & $P$-value \\
\hline Apical closure & $11(73.3 \%)$ & $7(63.6 \%)$ & $8(72.7 \%)$ & $8(72.7 \%)$ & 0.150 \\
\hline Root maturation & $10(66.7 \%)$ & $7(63.6 \%)$ & $2(18.1 \%)$ & $0(0.0 \%)$ & $0.001^{*}$ \\
\hline PCO & $2(13.3 \%)$ & $7(63.6 \%)$ & $2(18.1 \%)$ & $0(0.0 \%)$ & $0.003 *$ \\
\hline
\end{tabular}




\section{DISCUSSION}

The root sheath of Hertwig is usually sensitive to trauma but because of the degree of vascularity and cellularity in the apical region, root formation can continue even in the presence of pulpal inflammation and necrosis. Because of the important role of Hertwig's epithelial root sheath in continued root development after pulpal injury, every effort should be made to maintain its viability. In the event of necrosis and canal infection of immature teeth, it is necessary to disinfect the root canal and stimulate the formation of an apical barrier that would allow an adequate filling, i.e. an apexification procedure. Different techniques for apexification have been suggested, the most common being calcium hydroxide for an undetermined period of time ${ }^{(7,8,9)}$. Although it is hypothesized that debridement of the root canal and removal of the necrotic pulp tissue and microorganisms are the critical factors in apexification ${ }^{(10)}$. Some believe that instrumentation of immature teeth may in fact hamper root development and that is why it is advised that preparation of these canals should be done cautiously to avoid any trauma to the tissues around the apex ${ }^{(11,12)}$. In the present study, no instrumentation was performed in the root canals of revascularization group. This gentle treatment regimen was an attempt to conserve any viable tissues that may remain in the root canal system, which may harbor stem cells of apical papilla. This agrees with previous case reports where clinicians reported that during the treatment of immature teeth with periradicular abscess, the patient felt the insertion of a smooth broach into the canal before reaching the apex suggesting remaining partial vital pulpal tissue ${ }^{(2,3)}$, or vital pulp tissue and hemorrhage observed. Many authors also speculated that the remnants of the survived epithelial root sheath of Hertwig at the apices of immature teeth, after disinfection, might organize the apical mesodermal tissue into root components ${ }^{(14,15)}$.
On comparing apical closure, no statistically significant difference was detected in the prevalence of apical closure between the four subgroups This result goes in agreement with ${ }^{(16,17)}$ who showed convincingly that immature teeth clinically diagnosed with non-vital pulp with periradicular periodontitis or abscess can undergo apexogenesis, and conservative treatment may allow root development to reach their maturation. Shababhang et al.(1999) compared the efficacy of MTA with that of calcium hydroxide in the formation of hard tissue in immature roots of dogs. They concluded that MTA produced apical hard tissue formation with significantly greater consistency. Similarly, This result was also confirmed by Villa and Ferna'ndez, (2005); Pace et al., (2007) and Kubasad and Ghivari, (2011) who concluded that apexification with MTA often induced the formation of apical barrier with hard tissue and a mineralized barrier of apical tissue when used in contaminated canals of teeth with incomplete root formation. Moreover, Sheehy and Roberts, (1997) reported in a review of 10 studies that the use of calcium hydroxide for apical barrier formation was successful in 74-100\% of cases. Rafter, (2005) stated that the strongest predictor of rapid barrier formation was the rate of change of calcium hydroxide and a barrier also formed more rapidly in cases with narrower initial apical width.

Moreover, a statistically significant difference between root maturation in the four subgroups ( $\mathrm{P}$ value $=0.001)$ was found. where, revascularization with MTA and $\mathrm{Ca}(\mathrm{OH}) 2$ subgroups showed the highest prevalence of root maturation, $(66,7 \%$ and $63.6 \%$ respectively). While apexification with MTA showed lower prevalence of root maturation $(18.1 \%)$. These results go in agreement with many reports by Whittle (2000); Iwaya et al., (2001); Selden, (2002); Banchs and Trope, (2004); Chueh \& Huang, (2006) and Huang et al., (2008) who showed the potential of root maturation or progressive thickening of the dentinal walls of 
immature permanent teeth with nonvital pulp even with the presence of periradicular pathoses using the same treatment protocol.

The results of this study indicated that apexification with $\mathrm{Ca}(\mathrm{OH}) 2$ showed no root maturation at all since calcium hydroxide with its high $\mathrm{pH}$ is known to be toxic to vital cells and hence might damage the cells in its contact at the apex, which have regenerative capacity to heal periapical tissues. Another concern is that $\mathrm{Ca}(\mathrm{OH})_{2}$ may damage the HERS and thereby losing its ability to induce the nearby undifferentiated cells to become ododontoblasts.

Regarding all cases of unfavorable revascularization outcome, the possible explanation nevertheless, may be attributed to the inability of $\mathrm{NaOCl}$ solution to completely eradicate bacteria from infected root canals regardless of the concentration used ${ }^{(18,19)}$. Another possible explanation for poor root development might be failure to induce good bleeding into the canal. The absence of a blood clot has been shown to have a negative impact on successful revascularization of the pulp in an animal study by Thibodeau et al., (2007) and Nosrat et al., (2012). Some authors have also reported failure to induce bleeding ${ }^{(20,21)}$. This may be explained by the resolution of inflammatory reaction after dressing with the antibiotic mixture, making it more difficult to induce bleeding. Another reason might be related to the use of local anesthesia containing epinephrine that results in vasoconstriction. Using local anesthetics without vasoconstrictor facilitates bleeding after root canal disinfection. However, there are several reports of successful regenerative endodontic treatment and continued root development without bleeding induction by Shah et al., (2008) and Shin et al., (2009).

In the present study the outcome of regenerative endodontic treatment of necrotic immature teeth of some cases was lower than ideal with complete obliteration of the entire root canal space. This pulpal canal obliteration (PCO) showed statistically significant difference in the four subgroups $(\mathrm{P}$ value $=0.003)$. revascularization with $\mathrm{Ca}(\mathrm{OH}) 2$ showed the highest prevalence of PCO (63.6\%) followed by apexification with MTA subgroup (18.1\%). Revascularization with MTA showed lower prevalence $(13.3 \%)$ while apexification with $\mathrm{Ca}(\mathrm{OH}) 2$ showed no $\mathrm{PCO}$ at all.

This unfavorable PCO outcome was also reported by Chueh and Huang, (2006) who showed in their retrospective study complete root canal obliteration in 2 cases out of 23 immature necrotic teeth treated with calcium hydroxide within 17 to 59 months after initial treatment. In addition, the other 21 teeth showed partial obliteration of the root canal space in comparison with adjacent normal teeth. This could be explained on the basis that direct contact of $\mathrm{Ca}(\mathrm{OH})_{2}$ paste with the remaining vital pulp tissue in the canal created an environment conducive to the formation of calcific hard tissue barrier formed by osteo-cementum and occupied the pulp space therefore preventing the pulp tissue to regenerate and grow into that space. However, there were 3 studies by Cotti et al (2008), Cehreli et al (2011) in which calcium hydroxide was used and no root canal calcification/obliteration was reported. In addition, the complete root canal calcification/ obliteration has occurred at least within an average of 16 months after initial treatment. Therefore, the follow-up period of the study by Cehreli et al., (2011) might not be enough for a conclusion in this regard. Although complete root canal calcification/ obliteration is not mentioned as a failure in cases that have undergone regenerative endodontic treatment, it can cause serious challenges in case the involved tooth needs root canal therapy. Moreover, by filling the canal with calcium hydroxide, a physical barrier is created that prevents migration of multipotent undifferentiated mesenchymal cells into the canal and regeneration of tissues at the lateral dentinal walls. Whereas by using the antibiotic paste, the pulp tissue appears to be able to fill in the remaining canal space. 
When apexification procedure is attempted, the root canal is filled with a non-setting formulation of calcium hydroxide, until a hard tissue barrier forms at the apex. Because the pulp canal space is physically occupied by the material, there is no room for vital tissue to proliferate; in addition, $\mathrm{Ca}(\mathrm{OH})_{2}$ might not provide a suitable environment for host cell proliferation ${ }^{(24)}$. In addition, Nosrat, (2012) showed that the radiographic location of calcium hydroxide inside the root canal space influenced the root development. When calcium hydroxide was radiographically limited to coronal half of the root canal space, the increase in root wall thickness was greater than when it was placed beyond coronal half.

\section{CONCLUSIONS}

1. Revascularization is an effective technique for managing immature permanent teeth with apical periodontitis with appropriate case selection.

2. Revascularization technique offers several advantages over other established treatment protocols for the management of immature teeth with infected root canals.

3. Revascularization procedures may allow for the continued development of roots in immature teeth with necrotic pulps.

\section{REFERENCES}

1. American Association of Endodontists Glossary of endodontic terms, 7th edn. Chicago: American Association of Endodontists; 2003.

2. Iwaya SI, Ikawa M, Kubota M. Revascularization of an immature permanent tooth with apical periodontitis and sinus tract. Dent Traumatol 2001;17:185-7.

3. Banchs F, Trope M. Revascularization of immature permanent teeth with apical periodontitis: new treatment protocol? J Endod, 2004; 30:196-200.

4. Chueh L and Huang G. Immature teeth with periradicular periodontitis or abscess undergoing apexogenesis: a paradigm shift. J Endod 2006; 32: 1205-13.
5. Ding RY, Cheung GS, Chen J, Yin XZ, Wang QQ, Zhang CF. Pulp revascularization of immature teeth with apical periodontitis: a clinical study. J Endod 2009; 35:745-9.

6. Akgun OM, Altun C, Guven G Use of triple antibiotic paste as a disinfectant for a traumatized immature tooth with a periapical lesion: A case report. Oral Surg Oral Med Oral Pathol Oral Radiol Endod 2009; 108: 62-65

7. EstrelaC, Pimenta FC, I to IY and Bammann LL. In vitro determination of direct antimicrobial effect of calcium hydroxide. JOE, 2001; 24: 15-7.

8. Villa P, Fernández R. Apexification of a replanted tooth using mineral trioxide aggregate. Dent Traumatol 2005; 21: 306-308._ Blackwell Munksgaard, 2005.

9. Rafter M. Apexification: a review. Dent Traumatol 2005; $21: 1-8$.

10. Whittle M. Apexification of an infected untreated immature tooth. J Endod 2000; 26: 245-7.

11. Das S, Das AK and Murphy RA Experimental apexogenesis in baboons. Endod Dent Traumatol 1997; 13: 31-5.

12. Cooke C, Rowbotham TC. The closure of open apices in nonvital immature incisor teeth. British Dental Journal1988;165:420-1.

13. Kim ST, Abbott PV and McGinley P. The effects of Ledermix paste on discolouration of immature teeth. International Endodontic Journal 2000; 33:233-7.

14. Windley W, Teixeira F, Levin L, Sigurdsson A, Trope M. Disinfection of immature teeth with a triple antibiotic paste. J Endod 2005: 31, 439-43.

15. Sonoyama W, Liu Y, Yamaza T, Tuan RS, Wang S, Shi S. Characterization of the apical papilla and its residing stem cells from human immature permanent teeth: a pilot study. Journal of Endodontics 2008; 34: 166-71.

16. Lenzi $\mathrm{R}$ and Trope M. Revitalization procedures in two traumatized incisors with different biological outcomes. J Endod 2012; 38: 411-4.

17. Thibodeau B, Trope M. Pulp revascularization of a necrotic infected immature permanent tooth: case report and review of the literature. Pediatric Dentistry 2007; 29: 47-50.

18. Shuping GB, Ørstavik D, Sigurdsson A and Trope M. Reduction of intracanal bacteria using nickel-titanium rotary instrumentation and various medications. JOE 2000; 26: $751-5$. 
19. Radeva E, Indjov B. and Vacheva R. Antibacterial activity of intracanal medicaments against bacterial isolates in cases of acute periapical periodontitis. Journal of IMAB, $2^{\text {nd }}$ ed.; 2005.

20. Cehreli ZC, Isbitiren B, Sara S, Erbas G. Regenerative endodontic treatment (revascularization) of immature necrotic molars medicated with calcium hydroxide: a case series. J Endod 2011; 37: 1327-30.

21. Nosrat A, Negar H, and Kaveh O. Drawbacks and Unfavorable Outcomes of Regenerative Endodontic Treatments of Necrotic Immature Teeth: A Literature Review and Report of a Case. JOE (38); 10: October 2012
22. Shabahang S, Torabinejad M, Boyne PJ, Abedi HH and McMillan P. Apexification in immature dog teeth using osteogenic protein-1, mineral trioxide aggregate, and calcium hydroxide. JOE, 1999; 25: 1-5.

23. Sheehy EC, Roberts GJ. Use of calcium hydroxide for apical barrier formation and healing in non-vital immature permanent teeth: a review. Br Dent J 1997; 183: 241-6.

24. Laureys W, Beele H, Cornelissen R, Dermaut L. Revascularization after cryopreservation and autotransplantation of immature and mature apicoectomized teeth. Am J Orthod Dentofacial Othope 2001; 119: 346-52. 